\title{
MEDIA PENGENALAN BARONG BANGKUNG NGELAWANG DENGAN GAME 3D BARONG BANGKUNG RUNNER BERBASIS ANDROID
}

\author{
I Gede Suardika1; I.G.P Ditha Satria Dana2; I.G.N Wikranta Arsa3 \\ ${ }^{1}$ Sistem Informasi \\ Institut Teknologi dan Bisnis STIKOM Bali \\ http://stikom-bali.ac.id \\ suardika@stikom-bali.ac.id \\ ${ }^{2}$ Sistem Komputer \\ Institut Teknologi dan Bisnis STIKOM Bali \\ http://stikom-bali.ac.id \\ dithasatria1@gmail.com \\ ${ }^{3}$ Sistem Komputer \\ Institut Teknologi dan Bisnis STIKOM Bali \\ http://stikom-bali.ac.id \\ arsa@stikom-bali.ac.id
}

\begin{abstract}
Barong Bangkung is a tradition in Bali that is staged by going around the village or the term (ngelawang) by two dancers on certain days which are considered sacred or when a disease outbreak attacks the village without carrying a play and is accompanied by batel or tetamburan. Barong ngelawang development is now undergoing change. Barong ngelawang was originally sacred, but in its development Barong Ngelawang activities emerged which were carried out by children to entertain and make money. So it is necessary to create a media that can introduce the barong bangkung ngelawang tradition in accordance with its original religious tradition. The purpose of this study is to introduce the original tradition of Barong Bangkung ngelawang in the form of an Android-based $3 D$ game. In building Android-based Barong Bangkung Runner 3D Games using the development method of GDLC (Game Development Life Cycle) with the help of Unity 3D Game Engine software using $C$ \# (CSharp) programming language, Blender, Adobe Photoshop, and Audition. The modeling language used is UML (Unified Modeling Language). The results of this study succeeded in producing an Android-based Barong Bangkung Runner 3D Game. The game was tested by the Black Box method and the results of the game can run well on devices with $3 G B$ of RAM and above.
\end{abstract}

Intisari-Barong Bangkung adalah sebuah tradisi di Bali yang dipentaskan dengan berkeliling desa atau istilahnya (ngelawang) oleh dua orang penari pada hari-hari tertentu yang dianggap keramat atau saat terjadinya wabah penyakit menyerang desa tanpa membawakan sebuah lakon dan diiringi dengan gamelan batel atau tetamburan. Perkembangan Barong ngelawang kini mengalami perubahan. Semula Barong ngelawang yang sakral, tetapi dalam perkembangannya muncul kegiatan Barong ngelawang yang dilakukan anak-anak untuk menghibur dan mencari uang. Maka diperlukan untuk membuat sebuah media yang dapat mengenalkan tradisi barong bangkung ngelawang sesuai dengan tradisi aslinya yang religius. Tujuan dari penelitian ini yaitu untuk memperkenalkan tradisi asli dari Barong Bangkung ngelawang dalam bentuk sebuah game $3 D$ berbasis Android. Dalam membangun Game 3D Barong Bangkung Runner Berbasis Android menggunakan metode pengembangan GDLC (Game Development Life Cycle) dengan bantuan perangkat lunak Unity 3 Dame Engine dengan menggunakan bahasa pemrograman C\# (C-Sharp)., Blender, Adobe Photoshop, dan Audition. Bahasa pemodelan yang digunakan adalah UML (Unified Modelling Language). Hasil dari penelitian ini berhasil menghasilkan Game 3D Barong Bangkung Runner Berbasis Android. Pengujian Game ini menggunakan metode Black Box dan hasilnya game dapat berjalan baik pada perangkat dengan RAM $3 G B$ ke atas

Kata Kunci: Game, Barong Bangkung, Android, Unity 3D, GDLC.

\section{PENDAHULUAN}

Barong dipercayai oleh Masyarakat Bali sebagai makhluk mitos, representasi Tuhan, untuk melindungi alam semesta dari Murka Dewi Durga 
yang dapat berbentuk Barong Ket atau Barong Keket, Barong Landung, Barong Macan (Harimau), Barong Kedingkling, Barong Gajah (Gajah), Barong Asu (Anjing), Barong Brutuk dan Barong Bangkung (Karyambara Putra, 2018).

Kata ngelawang dalam ungkapan barong ngelawang berasal dari kata dasar 'lawang', yang berarti pintu. Awalan 'nge' berarti pergi ke. Dengan demikian, ungkapan barong ngelawang berarti pergi dari pintu ke pintu, dari rumah ke rumah, dan dari desa ke desa untuk melakukan tarian barong (Sukerna, Wirawan, Kumbara, \& Sukerta, 2016). Umumnya Barong Bangkung ini dipentaskan dengan berkeliling desa atau istilahnya (ngelawang) oleh dua orang penari pada hari-hari tertentu yang dianggap keramat atau saat terjadinya wabah penyakit menyerang desa tanpa membawakan sebuah lakon dan diiringi dengan gamelan batel atau tetamburan. Namun pada perkembangannya Barong ngelawang kini mengalami perubahan. Semula barong ngelawang yang sakral, tetapi dalam perkembangannya muncul kegiatan barong ngelawang yang dilakukan anak-anak untuk menghibur dan mencari uang. Perubahan dalam tradisi barong ngelawang salah satunya terjadi di kawasan pariwisata Ubud, Gianyar, Bali. Di daerah ini tarian sakral barong telah dilakukan setiap kali hari-hari raya Galungan dan Kuningan dirayakan. Namun, dalam perkembangannya tarian barong juga telah dilakukan oleh anak-anak sebagai hiburan dari mana mereka dapat menghasilkan uang (Sukerna, Wirawan, Kumbara, \& Sukerta, 2016).

Pertunjukan Barong Bangkung selalu diiringi dengan gamelan batel. Gamelan Batel terdiri dari kendang, cengceng, gong, dan kempur, klenang dan kajar. Bunyi dari gamelan batel mengajak menantang mengganggu barong bangkung. Barong bangkung menari dan meliukliuk mengikuti irama gamelan. Biasanya barong bangkung ini dibawa keliling berjalan kaki dengan diiringi gong yang bunyinya bisa diartikan menantang untuk diganggu. Ini berarti setiap ada orang yang mengganggu barong tersebut, maka barong itu akan marah dan mengejar. Dalam kepercayaan masyarakat Bali, memainkan kesenian ini di depan atau di dalam rumah bisa menghilangkan hawa-hawa negatif di lingkungan kita atau dengan kata lain semacam tolak bala. Lingkungan di sekitar rumah/pekarangan rumah menjadi bersih dari hawa-hawa negative. Aksesoris yang dikenakan pada Barong Bangkung cenderung unik, bagian mulutnya mempunyai taring panjang di rahang atas maupun bawahnya, menariknya, mulut ini dapat digerakan yang umumnya berfungsi memperindah tarian dengan suara khas dari mulutnya ketika rahang atas dan bawahnya di benturkan. Selain itu, mulut ini juga digunakan untuk menggigit orang yang dikejar saat menantangnya (KA., 2012).

Melihat permasalahan di atas, maka dipandang perlu untuk membuat sebuah media yang dapat mengenalkan tradisi barong bangkung ngelawang sesuai dengan tradisi aslinya yang religius, agar masyarakat dapat mengetahui tradisi asli dari barong bangkung itu sendiri melalui perantara game dan juga dapat dijadikan sebagai media hiburan. Penelitian sebelumnya yang dilakukan oleh I Wayan Pasek Suartiawan, dkk, pada tahun 2016 yang bertujuan untuk menumbuhkan dan memberikan informasi kepada anak-anak bahwa tradisi ngelawang sangat menyenangkan, dapat menambah banyak teman media komunikasi visual yang efektif, di mana penelitian ini menggunakan beberapa metode seperti kepustakaan, kajian internet, observasi, dokumentasi, dan didukung dengan media kampanye seperti film pendek, $\mathrm{x}$ banner, poster, buku pop up, maskot, paper bag, t-shirt, pin, gantungan kunci, booth, sehingga diharapkan kebudayaan di Bali khususnya budaya ngelawang mendapat dukungan dan pelestarian dari masyarakat (Pasek Suartiawan, Suryanatha, \& Sagung Intan Pradnyanita, 2016). Penelitian lain yang dilakukan oleh Suarsini pada tahun 2018 yang bersifat penelitian deskriptif dan kualitatif mengkaji tentang bentuk dan makna serta pola pikir masyarakat Desa Pakraman Asak Pagutan terhadap tradisi Ngelawang. Penelitian ini mendeskripsikan informasi kebahasaan secara perspektif etnolinguistik yang ada dalam tradisi Ngelawang. Metode observervasi partisipatif dan metode wawancara digunakan sebagai metode pengumpulan data, metode distribusional, padan, dan fenomenologis digunakan sebagai metode dalam menganalisis data. Penyajian data dilakukan dengan metode informal dan formal. Penelitian ini memperoleh hasil bahwa "konsep dan prosesi tradisi Ngelawang di Desa Pakraman Asak Pagutan agak berbeda atau mengalami pergeseran dibanding dengan yang dilakukan di Bali, karena implementasinya, penggunaan istilah dalam tradisi Ngelawang didapat berdasarkan ranah yakni ranah alat, sarana upacara dan upakara, pelaku, proses, dan ranah waktu" (Suarsini, 2018).

Penelitian ini menggunakan media game berbasis Android, mengingat perkembangan game saat ini, tidak berbanding lurus dengan kemunculan game-game yang bertemakan tradisi/kesenian Bali. Padahal banyak sekali tema tradisi/kesenian Bali yang dapat dijadikan game. Saat ini game-game yang beredar masih cenderung untuk hiburan saja. Hal tersebut dikarenakan industri game masih di dominasi oleh developer asal luar negeri. Masih sedikitnya developer asal 
dalam negeri terutama developer asal Bali mengakibatkan kurangnya game-game yang mengangkat tradisi Bali. Padahal dengan perkembagan smartphone saat ini, seharusnya mampu untuk mempublikasikan atau mengenalkan tradisi-tradisi bali ke seluruh dunia melalui perantara game. Salah satu tradisi Bali yang menarik untuk dijadikan game yaitu Barong Bangkung.

Melalui latar belakang di atas maka akan dibangun game berjudul "Media Pengenalan Barong Bangkung Ngelawang dengan Game 3D Barong Bangkung Runner Berbasis Android".

\section{BAHAN DAN METODE}

Adapun metode penelitian yang digunakan adalah dengan menggunakan metodelogi Game Development Life Cycle (GDLC). Metode GDLC yang ditawarkan oleh Heather Chandler dianggap sebagai pendekatan yang paling cocok dalam penelitian ini, karena langkah-langkahnya sesuai dengan kondisi dan tujuan penelitian. Langkahlangkah tersebut dditunjukkan oleh Sumber: (Ramadan, 2013)

Gambar 1 (Ramadan, 2013).

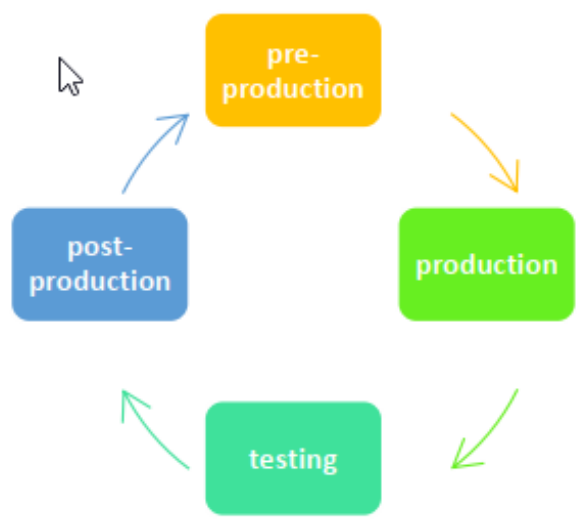

Sumber: (Ramadan, 2013)

Gambar 1. Metode GDLC

Tahap pra-produksi dilakukan penentuan desain game dan perencanaan proyek seperti konsep game yang meliputi: judul game, genre game, target pasar. Game ini dikembangkan dengan genre game Infinite Runner 3D, di mana target pasar adalah pengguna smartphone Android di seluruh Indonesia. Model 3D merupakan representasi dari objek 3D dengan menggunakan kumpulan titik-titik yang berada pada ruang 3D yang terhubungan oleh berbagai macam bentuk geometri seperti contohnya segitiga, garis, kurva, dan lain-lain (Blackman, 2011). Dalam perancangan game digunakan UML, sebuah "bahasa" yang telah menjadi standar dalam industri untuk visualisasi, merancang dan mendokumentasikan sistem piranti lunak ( $\mathrm{T}$ \& Begg, 2010) mengingat bahasa pemrograman C\# yang dipakai dalam implementasi adalah bahasa pemrograman yang berorientasi objek atau Object Oriented Programming (OOP).

Tahap produksi berperan sebagai proses inti, yang terdiri atas penciptaan aset, pembuatan source code, dan integrase dari kedua elemen tersebut. Dalam perancangan aplikasi Game Barong Bangkung Runner Berbasis Android, software yang digunakan untuk membangun game ini adalah Unity 3D 2017.1.0 sebagai game engine utama, Visual Studio 2017 dalam game ini digunakan sebagai Script Editor, Blender 3D 2.79 digunakan untuk membuat model 3D dari game ini, Adobe Photoshop CC 2018 digunakan untuk membuat assets pendukung seperti sketsa character, obyek 2D seperti tombol-tombol, panel menu dan membuat texture dari obyek-obyek 3D. Sistem inti engine Unity 3D menggunakan beberapa pilihan bahasa pemrograman, diantaranya C\# dan javascript dan menyediakan beberapa alat untuk mempermudah pengembangan yaitu Unity Tree dan terrain creator untuk mempermudah pembuatan vegetasi dan terrain (Ully A, 2012).

Pengujian dilakukan ketika pengembangan game dilakukan untuk satu siklus (Ramadan, 2013). Pengujian Game dilakukan dengan dua tahap yaitu Alpha Testing menggunakan metode Black Box Testing dan tahap Beta Testing dengan melakukan pengujian yang dilakukan secara obyektatif pada berbagai perangkat yang memiliki spesifikasi yang berbeda.

\section{HASIL DAN PEMBAHASAN}

Penelitian ini menggunakan Metode GDLC. Adapun hal-hal yang telah dilakukan pada fase-fase metode GDLC tersebut dapat dijelaskan sebagai berikut.

\section{A. Pre-Production}

Pada tahap ini dilakukan penentuan konsep game dan pembuatan rancangan game menggunakan UML. Game 3D Barong Bangkung Runner merupakan permainan yang meminta pemain untuk memerankan Barong Bangkung dengan misi menyelamatkan warga desa dari hawa negatif Celuluk dan mengharuskan melawan Celuluk di akhir permainan. Pemain dapat mengontrol gerak dari Barong Bangkung dengan cara melakukan swipe ke kanan untuk bergeser ke arah kanan, swipe ke kiri untuk bergeser ke arah kiri, swipe ke atas untuk melompat, dan swipe ke bawah untuk merunduk. Game ini memiliki 3 buah 
jalur yang mana di setiap jalurnya terdapat item yang dapat di ambil yaitu loloh cemcem dan gong. Setiap item yang berhasil di ambil akan memunculkan popup keterangan yang berisikan informasi-informasi dari item yang di ambil. Jika pemain berhasil mengumpulkan 100 loloh cemcem maka, pemain akan mendapatkan shield yang berguna agar pemain bisa kebal terhadap rintangan yang ada. Pemain juga memiliki level kemarahan yang mana jika level kemarahan masih tersedia maka, pemain dapat lanjut terus bermain game. Jika level kemarahan habis maka akan dinyatakan kalah.

Terdapat juga warga-warga yang berdiri di depan rumahnya yang sedang meminta pertolongan agar di hilangkan hawa-hawa negatif yang merasuki dirinya. Jika pemain berhasil menyelamatkan 30 warga maka, pemain akan mendapat tambahan 1 nyawa sebagai bonusnya. Celuluk akan muncul jika pemain telah mencapai batas akhir dari arena. Celuluk akan menyerang Barong Bangkung dengan mengeluarkan rerajahan dan bambu sebagai senjatanya. Ia akan menyerang selama 15 detik, tugas dari Barong Bangkung yaitu menghalau serangan dari Celuluk. Jika berhasil bertahan Barong Bangkung baru di perbolehkan untuk menyerang Celuluk. Cara menyerangnya yaitu dengan cara melompati Celuluk. Jika berhasil melompati Celuluk maka darah Celuluk akan berkurang 1.

Pada awal permainan, pemain akan diperlihatkan story dari Barong Bangkung Ngelawang. Pemain dapat men-skip story dengan cara men-klik panel story. Setelah story selesai pemain di arahkan ke halaman tutorial. Pada halaman tutorial pemain diajarkan cara bermain permainan ini. Setelah selesai melakukan tutorial, pemain langsung di arahkan ke halaman gameplay. Bagian story dan tutorial hanya muncul sekali pada saat pemain baru menginstall game. Setelah itu saat pemain menekan tombol play yang ada di halaman utama, pemain akan langsung di arahkan ke halaman gameplay.

Rancangan game dapat dilihat pada Gambar 2 sampai dengan Gambar 4. Sumber:

Gambar 2 merupakan gambaran Use Case Diagram dari Game Barong Bangkung Runner Berbasis Android. Pada Use Case Diagram Barong Bangkung Runner Berbasis Android akan di jelaskan bagaimana proses yang terjadi pada saat pemain memulai menjalankan permainan ini. Saat game ini baru dijalankan, maka pemain akan berada di main menu. Pada main menu terdapat 4 buah menu yaitu Play, Settings, About, Exit. Saat pemain memilih menu Play dan pemain baru pertama kali memainkan Game ini, pemain akan terlebih dahulu di arahkan ke halaman story, setelah story selesai kemudian pemain di tunjukkan cara bermain/tutorial, setelah selesai pemain langsung masuk ke dalam gameplay.

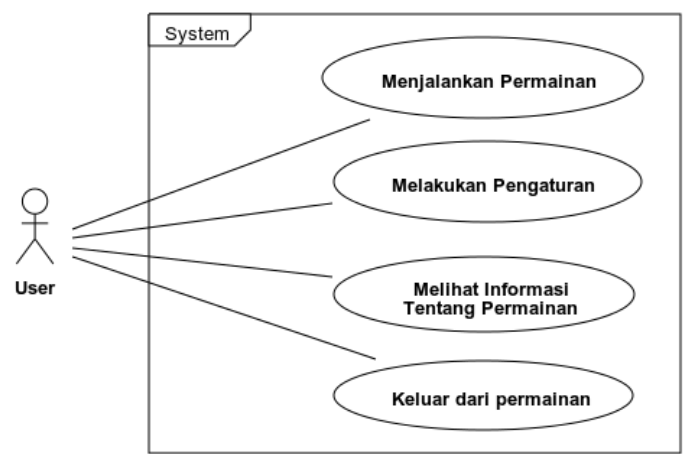

Sumber: (Ditha Satria Dana, Suardika, \& Wikranta Arsa, 2018)

Gambar 2. Use Case Diagram

Sequence diagram menggambarkan interaksi antara obyek di dalam dan disekitar sistem (termasuk user, display, dan sebagainya). Sequence diagram biasanya digunakan untuk menggambarkan skenario atau rangkaian langkahlangkah yang dilakukan sebagai respon dari sebuah event untuk menghasilkan output tertentu. Sequence diagram Menjalankan Permainan akan menjelaskan alur dari bagaimana pemain melakukan interaksi pada tombol Play. Gambaran sequence diagram Menjalankan Permainan dapat dilihat pada Gambar 3 yang merupakan gabaran dari proses ketika pemain menekan tombol Play. Setelah pemain menekan tombol Play, Sistem akan memproses dan melanjutkan ke dalam scene play. Pada scene play sistem mengecek terlebih dahulu ke dalam story data. Jika di dalam data storage story value masih false maka, sistem akan terlebih dahulu menampilkan scene story. Setelah pemain men-skip story, sistem akan menampilkan tutorial. Setelah pemain selesai memainkan tutorial sistem langsung menuju ke dalam permainan. Jika jarak tempuh pemain telah sampai batas yang di tentukan yaitu sejauh 315 meter maka, sistem akan memunculkan enemy(celuluk).

Jika nyawa dari pemain atau level kemarahan dari pemain sama dengan 0 maka, sistem akan menampilkan panel game over. Jika nyawa dari celuluk sama dengan 0 maka, sistem akan menampilkan panel win stage. Jika pemain menekan tombol pause yang ada di dalam gameplay maka sistem akan melakukan pause game. 


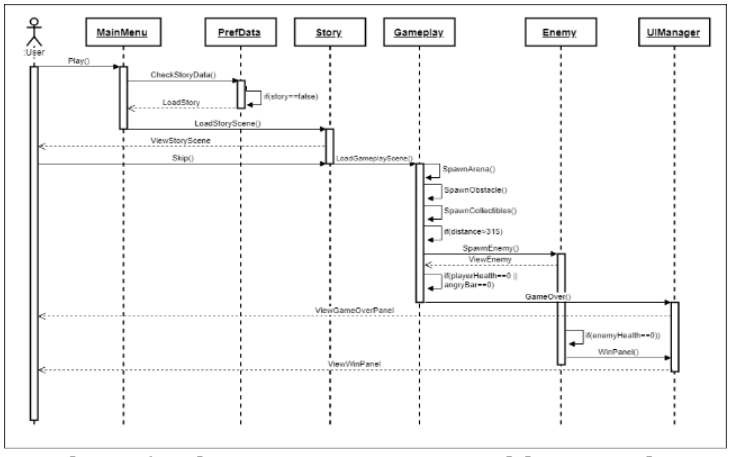

Sumber: (Ditha Satria Dana, Suardika, \& Wikranta Arsa, 2018)

Gambar 3. Sequence Diagram

Class diagram dari Game 3D Barong Bangkung Runner Berbasis Android ditunjukkan oleh Sumber:

Gambar 4.

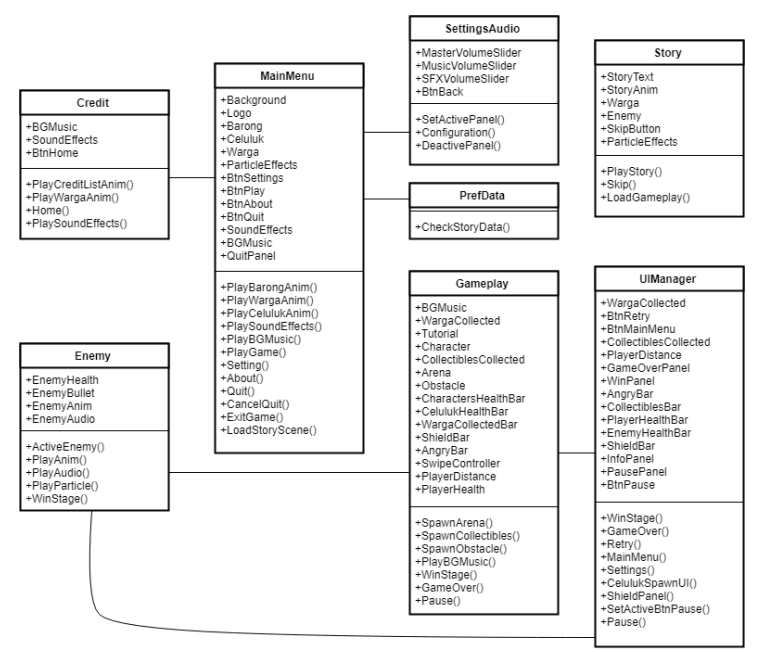

Sumber: (Ditha Satria Dana, Suardika, \& Wikranta Arsa, 2018)

Gambar 4. Class Diagram

\section{B. Production}

Setelah sistem dianalisis dan didesain secara rinci, maka akan dilanjutkan menuju tahap implementasi. Tahap implementasi sistem merupakan suatu langkah dalam menerjemahkan perancangan sistem yang telah dibuat kedalam kode program, sehingga dapat menghasilkan sistem yang sesuai dengan rancangan sebelumnya. Implementasi bertujuan untuk mengkonfirmasi modul-modul perancangan, sehingga pengguna dapat memberikan masukkan kepada pembangun sistem.

Sesuai dengan perancangan, Game 3D Barong Bangkung Runner Berbasis Android ini terdiri dari beberapa tampilan dan menu yaitu
Splash Screen, Main Menu, Story, Tutorial, Gameplay, Celuluk Spawn, Pause Menu, Win Stage, Game Over, Info Panel, Options Menu, About, dan Quit Panel.

Pada tampilan Main menu terdapat 4 buah tombol yaitu Play, Settings, About, dan Quit. Jika tombol Play ditekan maka game akan menuju ke dalam permainan. Jika tombol Settings ditekan maka, game akan memunculkan popup settings. Jika tombol About ditekan maka, game akan mengarahkan ke halaman About game. Jika tombol quit di tekan maka akan menutup game. Tampilan Main Menu terdapat pada Gambar 5 di bawah ini.

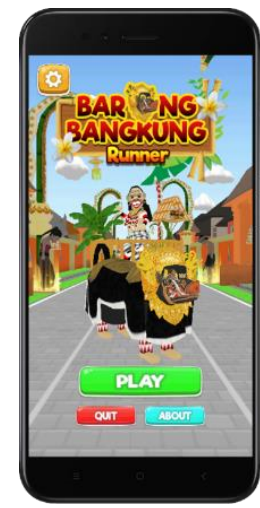

Sumber: (Ditha Satria Dana, Suardika, \& Wikranta Arsa, 2018)

Gambar 5. Tampilan Main Menu

Pada tampilan Story menampilkan panel yang berisikan informasi mengenai story. Pemain dapat men-skip story dengan mengklik panel story. Setelah beberapa saat akan muncul obyek celuluk. Celuluk akan memberikan kekuatan magis kepada warga. Satu-satunya yang dapat menolong warga dari kekuatan magis adalah barong bangkung. Setelah story selesai, pemain langsung di arahkan ke dalam gameplay. Tampilan story terdapat pada Gambar 6.

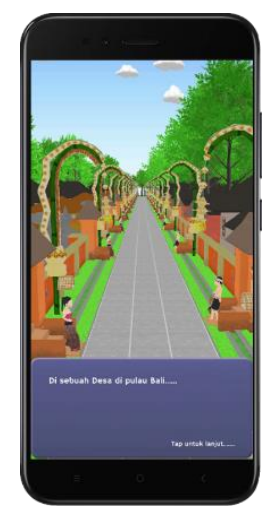

Sumber: (Ditha Satria Dana, Suardika, \& Wikranta Arsa, 2018)

Gambar 6. Tampilan Story 
Pada tampilan gameplay terdapat warga yang berdiri di depan rumahnya sedang terkena efek negatif dari celuluk. Warga tersebut berada di sisi kanan dan kiri dari karakter. Penempatan warga sendiri secara acak laki-laki atau perempuan. Jika pemain berhasil menolong warga hingga total 30 warga maka, pemain akan mendapatkan tambahan 1 nyawa. Terdapat beberapa obstacle di dalam game yang harus di lewati oleh pemain dan juga terdapat loloh cemcem yang berderet di tengah jalan yang dapat di ambil oleh karakter. Jika karakter berhasil mengumpulkan total 100 loloh cemcem maka karakter akan mendapatkan shield yang dapat melindungi karakter dari rintangan yang ada selama 10 detik. Pemain juga memiliki sebuah level kemarahan. Level kemarahan akan terus berkurang jika pemain tidak mendapatkan gong yang ada di dalam permainan. Pada di tengahtengah permainan akan muncul gong-gong di waktu-waktu tertentu yang dapat di ambil oleh pemain agar level kemarahan dari pemain tidak habis. Pada tampilan gameplay terdapat informasi jumlah warga yang terselamatkan, total loloh cemcem yang berhasil di ambil, jumlah nyawa dari pemain, jarak yang telah di tempuh, level kemarahan dari barong, shield bar, serta tombol pause yang berada di pojok kanan atas game. Tampilan gameplay terdapat pada Gambar 7.

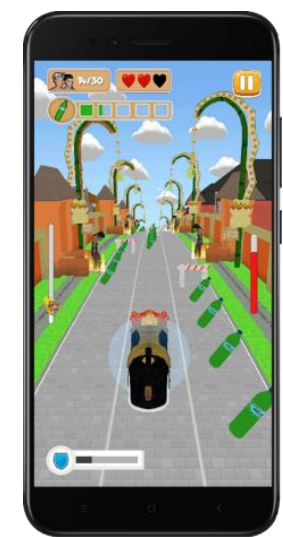

Sumber: (Ditha Satria Dana, Suardika, \& Wikranta Arsa, 2018)

Gambar 7. Tampilan Gameplay

Pada tampilan info panel terdapat sebuah image serta text informasi dari obyek yang di ambil. Terdapat tombol yang di berfungsi untuk menutup panel informasi. Tampilan Info Panel terdapat pada Gambar 8.

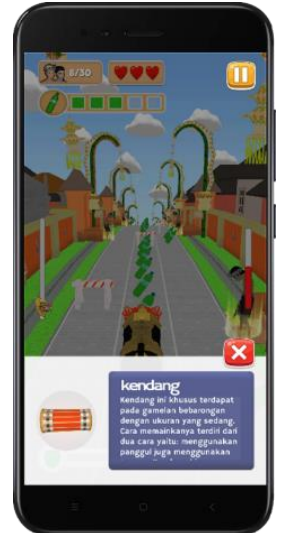

Sumber: (Ditha Satria Dana, Suardika, \& Wikranta Arsa, 2018)

\section{Gambar 8. Tampilan Info Panel}

Jika pemain telah berlari sejauh 315 meter maka, celuluk akan datang dan siap melawan barong bangkung. Celuluk mengeluarkan rerajahan dan bambu sebagai alat serang. Darah dari celuluk ada di pojok kiri atas game. Tampilan Celuluk Spawn terdapat pada Gambar 9.

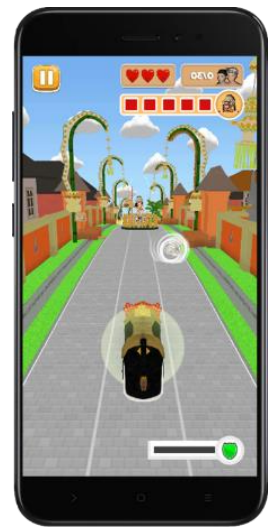

Sumber: (Ditha Satria Dana, Suardika, \& Wikranta Arsa, 2018)

\section{Gambar 9. Tampilan Celuluk Spawn}

Pada tampilan win stage akan memunculkan sebuah panel yang mana pada bagian panel tersebut akan menampilkan informasi kemenangan dari pemain. Pada bagian atas panel terdapat teks yang mmemberikan informasi bawa pemain telah memenangkan permainan serta di bagian tengah terdapat logo dari barong bangkung sendiri. Terdapat juga 2 buah tombol yang berada di bagian bawah dari panel yaitu tombol retry yang berfungsi agar pemain dapat memainkan game lagi dari awal serta tombol main menu yang berfungsi agar pemain dapat kembali ke menu utama. Tampilan Win Stage terdapat pada Gambar 10. 


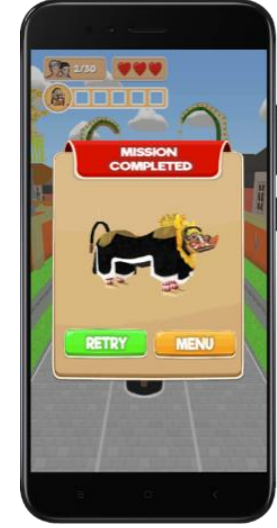

Sumber: (Ditha Satria Dana, Suardika, \& Wikranta Arsa, 2018)

\section{Gambar 10. Tampilan Win Stage}

Tampilan game over memunculkan panel yang berisikan informasi game over. Terdapat informasi total warga yang berhasil di selamatkan, jarak yang berhasil di tempuh dan total loloh cemcem yang berhasil di ambil. Terdapat 2 buah tombol yaitu tombol retry dan tombol main menu. Tampilan gameover terdapat pada Gambar 11.

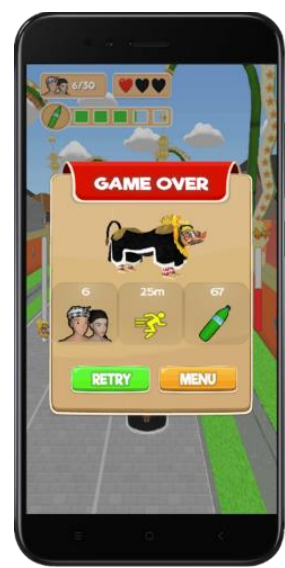

Sumber: (Ditha Satria Dana, Suardika, \& Wikranta Arsa, 2018)

Gambar 11. Tampilan Gameover

\section{Testing}

Pada tahap pengujian alpha testing, game harus bebas dari error atau bug, oleh karena itu game harus diuji coba terlebih dahulu untuk menemukan error atau bug yang mungkin terjadi, pada pengujian alpha testing ini menggunakan metode white box testing dan blackbox testing.

Pada tahapan pengujian alpha testing dengan menggunakan metode blackbox testing dimana salah satu klasifikasi pengujian blalck box yaitu klasifikasi penerimaan pengguna (user acceptance), pada jenis pengujian ini game ini akan diserahkan kepada user untuk mengetahui apakah game memenuhi harapan pengguna dan bekerja seperti yang diharapkan. Berdasarkan hasil pengujian pada alpha testing dengan menggunakan metode black box testing dapat disimpulkan bahwa game yang dibangun dinyatakan bebas dari error maupun bug dan secara fungsional memberikan hasil yang sesuai dengan apa yang diharapkan.

Beta testing merupakan pengujian yang dilakukan secara obyektatif dimana game akan diuji secara langsung ke lapangan, dengan cara mengujinya di berbagai perangkat yang memiliki spesifikasi yang berbeda. Pada pengujian ini menekankan pengujian di sektor processor dan RAM.

Berdasarkan hasil pengujian pada beta testing yang diuji langsung oleh user umum dengan mencoba menjalankan game ini di beberapa device Android yang memiliki spesifikasi yang berbeda dan dapat disimpulkan bahwa game ini dapat berjalan dengan baik pada smartphone Android dengan minimal ram 3GB.

\section{KESIMPULAN}

Pada penelitian ini telah berhasil membuat dan menghasilkan suatu media yang dapat digunakan untuk mengenalkan tradisi ngelawang sesuai aslinya pada perangkat lunak berupa Game 3D Barong Bangkung Runner Berbasis Android. Game ini berhasil dibangun dengan menggunakan Unity 3D Game Engine dengan bahasa pemrograman C\# (C-Sharp). Dari hasil pengujian dengan metode Black Box dapat disimpulkan bahwa Game 3D Barong Bangkung Runner Berbasis Android ini berfungsi sesuai dengan yang diharapkan.

\section{REFERENSI}

Blackman. (2011). Beginning 3D Game Development with Unity. Apress.

Ditha Satria Dana, I. G., Suardika, I. G., \& Wikranta Arsa, I. G. (2018). Rancang Bangun Game 3 Barong Bangkung Runner Berbasis Android. Skripsi tidak diterbitkan, Institut Teknologi dan Bisnis STIKOM Bali, Denpasar.

KA., A. (2012, April). Barong Bangkung "Kesenian Bali dulu dan kini". Kemadha, III, 26-33.

Karyambara Putra, I. (2018). The Past and present; story of Barong Bangkung. Bali Tourism Journal (BTJ), 2(1), 19-22. 
Pasek Suartiawan, I. W., Suryanatha, T. B., \& Sagung Intan Pradnyanita, A. A. (2016, April 1). Perancangan Media Komunikasi Visual Untuk Menumbuhkan Budaya Ngelawang Bagi Anak-Anak Di Denpasar. Selaras Rupa, 1(1).

Ramadan, Y. W. (2013). Game Development Life Cycle Guidelines. International Conference on Advanced Computer Science and Information Systems.

Suarsini, N. (2018, Nopember). Tradisi Ngelawang pada Hari Raya Kuningan di Desa Pakraman Asak Pagutan: Sebuah Kajian Etnolinguistik. Jurnal Mabasindo, 2(2).

Sukerna, I. N., Wirawan, A. A., Kumbara, A. A., \& Sukerta, P. M. (2016, 2). TRANSFORMATION OF TRADITION OF BARONG NGELAWANG IN TOURISM AREA OF UBUD, GIANYAR, BALI. E-Jurnal Kajian Budaya, 9. Retrieved from http://ojs.unud.ac.id/index.php/kajian/ar ticle/view/23255

T, C., \& Begg. (2010). Database Systems: A Practical Approach to Design, Implementation and Management. Edisi Kelima. Massachusetts: Addison-Wesley.

Ully A, S. B. (2012). Pembuatan Aplikasi Tata Ruang Tiga Dimensi Gedung Serba Guna Menggunakan Teknologi Virtual Reality [Studi Kasus: Graha ITS Surabaya]. Jurnal Teknik ITS. 